\title{
The Topographical Changes Accompanying Earthquakes and Volcanic Eruptions.*
}

THE twenty-sixth, and nominally the last, part of 1 the Publications of the Earthquake Investigation Committee appeared in 1908. Though we have had to wait more than twenty years for the number that should have preceded it, it may be said at once that geologists have gained greatly by the delay, for Prof. Imamura, the well-known secretary of the Committee, has been able to avail himself of many valuable recent observations, and especially of those of the Kwanto earthquake of 1923 and the Tango earthquake of 1927, and the eruptions of the Usu-san in 1910 and the Sakura-jima in 1914. It is not too much to say that his memoir is likely to prove one of the classics of seismology. In these pages Prof. Imamura has described the changes that have occurred about the times of so many as 26 Japanese earthquakes, in 12 of which (from 1891 to 1927) the changes have been measured by one or more series of subsequent precise levellings. As might be expected in a young country like Japan, the changes are of two kinds, which he terms chronic and acute. The latter, of course, are associated with earthquakes. The chronic changes may prepare the way for the acute earthquake changes, but an example of remarkable interest, investigated by the late Prof. Yamasaki, is given in which chronic changes occur apparently alone.

The district in question lies along the coast of the Japan Sea in the provinces of Etigo and Sinano, and extends about fifty miles to the east of the lofty Hido range. It consists of two large blocks separated by a deep depression. The series of precise levellings were carried out first in 1894, and they have been repeated in 1927. During this interval, in 1897 and 1918 , there were two strong shocks, but with neither was there any formation of new clefts or fault-lines. Yet a comparison of the two surveys has revealed the facts that, with a few trifling exceptions, both blocks have subsided, and that in each the amount of subsidence decreases gradually from west to east. In the western block, it is $94 \mathrm{~mm}$. at the west end and $38 \mathrm{~mm}$. at the east end, where, along an old fault, it suddenly increases to $113 \mathrm{~mm}$. In the eastern block, the subsidence is $96 \mathrm{~mm}$. at the west end, while at the east end there is a rise of $4 \mathrm{~mm}$., succeeded, again along an old fault, by a sudden depression of $70 \mathrm{~mm}$.

In the present notice, it is only possible to refer briefly to some of the interesting conclusions at

* Earthq. Inves. Com. Publ. in For. Langs., No. 25, pp. 1-143, 1930. which Prof. Imamura arrives. While most of the earthquakes with which topographical changes were associated were of destructive strength, a few (such as the Susaka earthquake of 1897 and the Oomati earthquake of 1918) resulted in no loss of life. As a rule, elevations of the land are confined to formations of Tertiary or more recent age, depressions to formations of pre-Tertiary age. The changes considered consist, for the most part, of discontinuous tiltings of consecutive mosiac blocks, but, in some earthquakes, as in the Kwanto earthquake of 1923 , there is also a rotational movement about a vertical axis or bodily displacement in a vertical direction. Discontinuous tiltings of contiguous blocks result in the formation of faults or flexures along their boundaries. In local earthquakes, such a fault-system is simple, but, in great earthquakes, it may be extremely complex. Sometimes, as in the Mino-Owari earthquake of 1891, it consists of several segments arranged en échelon, in the earthquake mentioned crossing the whole of the Main Island. In others, as in the Kwanto earthquake of 1923 and the Tango earthquake of 1927, it is distributed over the epicentral area along pre-existing tectonic lines.

In the Kwanto district, there have been four great earthquakes during the last two thousand years, shortly after the beginning of the Christian era, and in 818,1703 , and 1923. Prof. Imamura summarises the changes at the last epoch and probably at each of the other epochs, as consisting of the following stages : (1) a practical absence of any tilting for a century or so; (2) slight chronic tilting for a few decades in the direction opposite to that in which it afterwards occurs, accompanied by many local earthquakes ; (3) slight reversed tilting, with more frequent and stronger local earthquakes; (4) pronounced acute tilting accompanying a disastrous earthquake; and (5) a repetition to and fro of the tiltings, which gradually diminish in magnitude until they cease.

The changes that precede, accompany, and follow volcanic eruptions have been measured in only two eruptions. The earlier changes are similar to those that occur before earthquakes. In the immediate neighbourhood of the volcanoes, they consist apparently of an upward bulge of the land, but essentially they are discontinuous tiltings of mosaic blocks as in great earthquakes. The principal difference lies in the leisurely way in which the volcanic changes take place as compared with the quick and sudden changes that occur with earthquakes.

C. Davison.

\section{Estimating Stream Flow from Evaporation.}

MR. FOLSE'S monograph referred to below * em1 bodies the data and results of a research begun in 1912 and continued until 1925 by the late Dr. John F. Hayford and completed by the author. To a certain extent, as stated by the author, it overlaps Publication No. 317 by Dr. Hayford.

The object of the investigation was to formulate laws governing the flow of streams and rivers on the basis of more specific laws of evaporation. The numerous intensive studies of evaporation pans of small area have been supplemented by an examination on the full scale of Nature and under natural conditions. For this purpose, each of the Great Lakes was considered as an evaporation pan and from day to day evaluations were made of the change of content, the

* A new Method of estimating Stream Flow: based upon a new Evaporation Formul By J.A. Fol Pp. $x i+237+22$ plates. (Washington, D.C.: Carnegie Institution, 1929.) 5 dollars.

No. 3173, VoL. 126] income and outgo including evaporation. From these observations it was found possible to segregate that part of the outgo which is evaporation, and to determine the laws of evaporation, and their application to the problem of stream flow.

The observations consisted of the daily mean elevations of the water surfaces, barometric pressures, wind velocities, temperatures, vapour pressures, and rainfalls.

The outcome of the investigation claimed by the author is briefly as follows :

(1) An evaporation formula has been derived which enables one to estimate the daily evaporation from any free, open surface of water in terms of air temperature, vapour pressure, and wind velocity.

(2) An estimate has been made of the constant part of the run-off into each of the Lakes Michigan, Huron, and Superior, from their respective drainage areas, and 